\title{
Acute fatal interstitial lung disease in two cases under treatment of crizotinib
}

\author{
Ali Murat Sedef, Fatih Köse, Ahmet Taner Sümbül, Ahmet Sezer, Ali Ayberk Beşen, Hüseyin Mertsoylu and Özgür Özyılkan \\ Department of Medical Oncology, Baskent University, Adana, Turkey
}

\section{Introduction}

Crizotinib is an orally active, small molecule tyrosine kinase inhibitor of anaplastic lymphoma kinase (ALK), mesenchymalepithelial transition factor (met), hepatocyte growth factor receptor (HGFR) and ROS1 proto-oncogene receptor tyrosine kinase (ROS-1) [1]. Crizotinib actively used in treatment of advanced stage non-small cell lung cancer (NSCLC) with modest increase in survival rates with low rate of serious side effects $[2,3]$. Phase trials reported interstitial lung disease (ILD) as most feared complication of crizotinib [4]. However, clinical course, predictive risk factors, and management strategies remain uncertain. Here, we describe two cases of advanced stage NSCLC with an acute form of crizotinib-induced ILD.

\section{Case 1}

A 62 year old man, who presented with hemoptysisin May 2014 was diagnosed as stage IV NSCLC (adenocarcinoma). Personal history was positive with 50 packet/year cigarette smoking, but negative for systemic disease and his laboratory evaluation was normal. Positron Emission Tomography (PET-CT) revealed bilateral metastatic lung nodules along primary mass at the upper lob of right lung and bulky mediastinal lymph node metastasis. Mutation analysis of tumor specimen showed EML4/ALK fusion gene mutation with FISH technique. He was treated carboplatin-paclitaxel and pemetrexed as the first and second line treatment, respectively. After disease progression, crizotinib was started at the fifth month of the diagnosis as a third line treatment. On the third day of the crizotinib treatment, he presented with rapidly progressive dyspnea. His physical examination showed hypoxemia (PulseO $79 \%)$, tachypnea $(31 / \mathrm{min})$, tachycardia $(120 /$ min) and diffuse crackles at the bilateral basal lung zones. PAAG and contrasted chest tomography were showed new extensive patchy consolidations and new extensive bilateral ground-glass appearance (Figures 1 and 2). Echocardiography was negative for systolic and diastolic dysfunction. Microbiological tests (sputum or blood cultures, serology tests for atypical pathogens as CMV PCR, galactomannan, Pneumocystis carinii and respiratory viral panel) were negative for any assaulting organisms. CRP and ProCalcitonin were measured as 189 $\mathrm{mg} / \mathrm{L}, 0,21 \mathrm{ng} / \mathrm{mL}$ respectively. After exclusion of common reasons, though, it is impossible to reach decisive diagnosis of drug induced pneumonitis with radiological and laboratory tests, we strongly suggested crizotinib induced ILD. High dose methyl-prednisolone ( $250 \mathrm{mg}$ /day) was started, and crizotinib was stopped. At the fourth day of steroid treatment, the patients hypoxemia and symptoms were regressed momentarily for 10 days. Then, his respiratory symptoms get worsen, intubation and mechanical ventilation support was required. We lost the patient with severe respiratory failure at the $20^{\text {th }}$ day of starting crizotinib.

\section{Case 2}

A70 year old man who presented with progressive cough associated with chest pain three months ago, was diagnosed as stage IV NSCLC (adenocarcinoma). His past history was positive for 30 packet/ year cigarette smoking, but negative for systemic disease and his laboratory evaluation was normal. His primary tumor was located at right lobe of the lung and systemic metastases of bone and multiple cranial metastases. He was treated with whole brain radiotherapy with a dose of $30 \mathrm{~Gy}$. His genomic tests revealed presence of an EML/ALK 4 fusion gene translocation. Crizotinib was started after palliative cranial radiotherapy at a dose of $250 \mathrm{mg}$ BID. On the $13^{\text {th }}$ day of treatment, he admitted with complain of rapidly progressive dyspnea. His vital signs were abnormal with severe hypoxemia (Pulse $\mathrm{O}_{2} 88 \%$ in room air), tachypnea $(29 / \mathrm{min})$, tachycardia $(130 / \mathrm{min})$. Physical examination revealed extensive crackles at the bilateral basal zones of the lung. PAAG and contrasted chest tomography showed new extensive bilaterally patchy consolidations and new extensive bilateral ground-glass appearance, respectively (Figures 3 and 4). No pathological microorganism was isolated either from sputum or other sites including multiple blood cultures. Serology test was positive for pneumocystis carinii. However, after the consultation with the department with thoracic and infectious disease, we suggested that patient's clinic picture couldn't be explained only by infectious process of Pneumocystis carinii. Thus, we stopped crizotinib completely, and $250 \mathrm{mg} /$ day methyl prednisolone was started with empirical

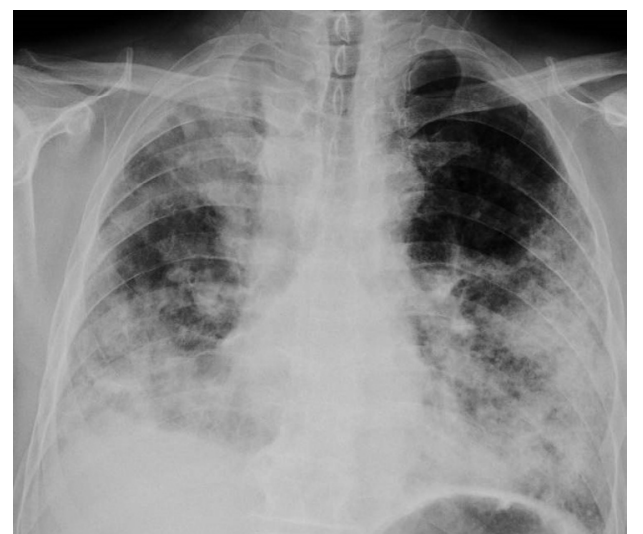

Figure 1. Direct PA chest radiograph showed new extensive patchy consolidations.

Correspondence to: Ahmet Taner Sümbül, Department of Medical Oncology, Baskent University, Adana, Turkey, E-mail: drtanersu@yahoo.com

Received: June 22, 2016; Accepted: July 11, 2016; Published: July 14, 2016 


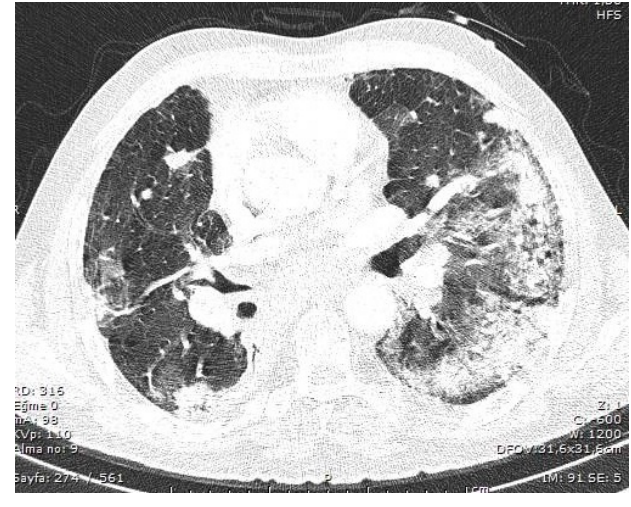

Figure 2. Chest CT scan performed on third day of crizotinib therapy showed new extensive bilateral ground-glass opacities and patchy consolidation.

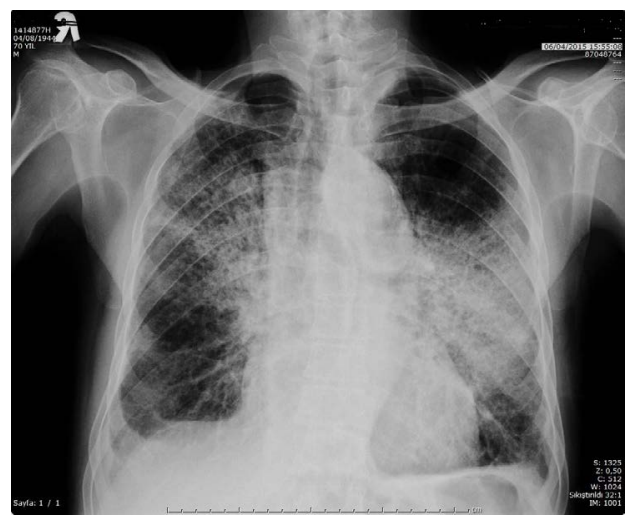

Figure 3. Direct PA chest radiograph showed new extensive bilaterally patchy consolidations

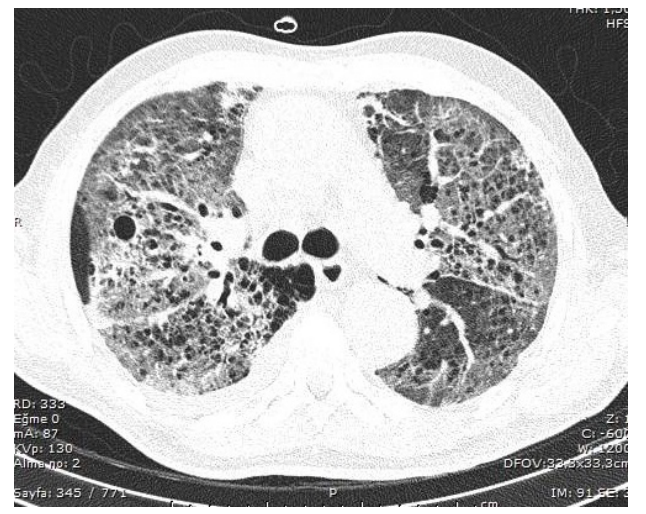

Figure 4. Chest CT scan performed on thirteenth day of crizotinib therapy showed new extensive bilateral ground-glass opacities and patchy consolidation.

trimethoprim-sulfamethoxazole. Patients clinical condition showed transitional improvement between 2 and $5^{\text {th }}$ day of high dose steroid. At the sixth day of admission, his condition deteriorates with increasing respiratory stress, the patient was connected to mechanic ventilation support. He was lost at the seventh day of admission with respiratory failure.

\section{Discussion}

Profile 1005 and 1014 clinical trials clearly showed that crizotinib is effective therapy in the first and second line treatment of ALK positive NSCLC $[2,3,5]$. In these studies, crizotinib is a generally well-tolerated drug, but significant adverse events also were reported. Though, the most frequently reported adverse effects were mild visual disturbances, nausea, vomiting, diarrhea, constipation, edema, and reduction in glomerular filtration rate, ILD is one of the well-known severe complications of the crizotinib with an occurrence rate of $1 \%$, along with mortality rate of $0.5 \%$. FDA reported that across all clinical trials $(n=1225), 31$ crizotinib-treated patients $(2.5 \%)$ had any grade ILD, 11 patients $(0.9 \%)$ had grade $3 / 4$ and 6 patients $(0.5 \%)$ had fatal ILD [2]. However, pathophysiological mechanism and predictive patient and tumor related risk factors for crizotinib-induced ILD are not well understood. Furthermore, most of the clinicians prefer close follow up of respiratory symptoms, especially for patients with background abnormality of respiratory function, with weekly lung X-ray examination. Any radiological and clinical abnormality suggesting ILD are promptly evaluated and crizotinib is discontinued.

In general terms, several molecular pathways has been proposed for TKI-induced ILD; direct injury of the of the cells in alveolar tissue with following recruitment of inflammatory cells, systemic release of cytokines along with excessive leakage of capillary material, hypersensitivity pneumonitis, and direct targeting of EGFR receptors on type II pneumocytes. But, TKI-induced ILD is a clinical diagnosis of exclusion after other etiology of respiratory failure including pneumonia, cardiogenic pulmonary edema, and diffuse alveolar hemorrhage. Yamaguchi et al. presented an autopsy case involving a patient with advanced HCC who developed rapidly progressive dyspnea on the $19^{\text {th }}$ day of sorafenib and lost on the $3^{\text {rd }}$ day of admission [6]. They described diffuse alveolar damage (DAD) which is indeed not specific for ILD but a common pathology of ARDS, sepsis, and shock. So, even open lung biopsy could not be enough to reach exact diagnosis with specific histopathological findings.

Crizotinib induced ILD in phase studies generally occurred within two months of treatment which suggest immunologically derived mechanism other than direct toxic effect of offending drug. This makes high dose steroid as an attractive treatment option. Though, authors of phase studies didn't make any comment on rechallenge of this effective therapy, Maka et al. and Asai et al. reported two cases of crizotinibinduced ILD in the $2^{\text {nd }}$ month of the successful rechallenge of offending drug after high dose steroid treatment. However, in our cases, ILD developed on the $3^{\text {rd }}$ and $13^{\text {th }}$ day of the treatment which is relatively short time compared to the current literature.

According to the best of our knowledge, our cases are in among the few reported cases of ILD which developed before $15^{\text {th }}$ day of crizotinib treatment and lost with rapid respiratory failure despite of high dose steroid treatment. Tamiya et al. and Watanebe et al. reported two cases of crizotinib induced ILD which developed $9^{\text {th }}$ and $16^{\text {th }}$ days after the onset of crizotinib treatment $[4,7]$. Both of these patients show rapid fatal clinical course and did not respond to high dose steroid treatment. On the other hand, retrospective analysis of 70 cases with gefitinib induced ILD published by Ando et al. showed male sex, a history of smoking, and co-existence of interstitial pneumonia as a significantly important predictive factors for gefitinib-induced ILD [8]. However, it remains ambiguous that these factors also related to crizotinib induced ILD. But, aforementioned cases along with our two cases have at least two of three risk factors.

In conclusion, our findings suggest that crizotinib induced ILD may have two distinct clinical presentation. First, acute form, which probably result of direct toxic effect of crizotinib, do not respond to steroid treatment, showing similar radiological abnormality with other types of ILD, and has highly fatal outcome. Second, classic form, 
which have immunological background, has good response to steroid treatment, again do not show any specific radiological abnormality, and may permit to rechallenge of crizotinib after resolution of toxicity. Therefore, deeper understanding of pathophysiological mechanism and reevaluation of the cases in phase studies those who developed lung toxicity may be required to define exact predictive factors of crizotinib induced ILD in this context.

\section{Conflict of interest}

The authors declared no conflict of interest.

\section{References}

1. Chen X, Zhou JY, Zhao J, Chen JJ, Ma SN, et al. (2013) Crizotinib overcomes hepatocyte growth factor-mediated resistance to gefitinib in EGFR-mutant non-smallcell lung cancer cells. Anticancer Drugs 24: 1039-1046. [Crossref]

2. Solomon BJ, Mok T, Kim DW, Wu YL, Nakagawa K, et al. (2014) First-line crizotinib versuschemotherapy in ALK-positivelungcancer. $N$ Engl J Med 371: 2167-77. [Crossref]
3. Riely GJ, Evans TL, Salgia R, Ou SI, Gettinger SN, et al. (2012) Global Phase II Study of Crizotinib in Advanced ALK-positive Non-small Cell Lung Cancer. Presented at the IASLC Chicago Multidisciplinary Symposium in Thoracic Oncology 2012, September 6-8, Chicago, IL.

4. Watanabe N, Nakahara Y, Taniguchi H, Kimura T, Kondoh Y, et al. (2014) Crizotinibinduced acute interstitial lung disease in a patient with EML4-ALK positive non-small cell lung cancer and chronic interstitial pneumonia. Acta Oncol 53: 158-60. [Crossref]

5. Shaw AT, Kim DW, Nakagawa K, Seto T, Crino L, et al. (2013) Crizotinib versus chemotherapy in advanced ALK-positive lung cancer. $N$ Engl J Med 368: 2385. [Crossref]

6. Takashi Y, Toshihito S, Chika M, Ryosuke I, Rinako K, et al. (2015) Interstitial pneumonia induced by sorafenib in a patient with hepatocellular carcinoma: An autopsy case report. Oncol Lett 9: 1633-1636. [Crossref]

7. Tamiya A, Okamoto I, Miyazaki M, Shimizu S, Kitaichi M, et al. (2013) Severe acute interstitial lung disease after crizotinib therapy in a patient with EML4-ALK-positive non-small-cell lung cancer. J Clin Oncol 2013 31: e15-7. [Crossref]

8. Ando M, Okamoto I, Yamamoto N, Takeda K, Tamura K, et al. (2006) Predictive factors for interstitial lung disease, antitumor response, and survival in non-small-cell lung cancer patients treated with gefitinib. J Clin Oncol 24: 2549-56. [Crossref]

Copyright: ${ }^{2} 2016$ Ali Murat SEDEF. This is an open-access article distributed under the terms of the Creative Commons Attribution License, which permits unrestricted use, distribution, and reproduction in any medium, provided the original author and source are credited. 